\title{
El derecho a defender el medio ambiente: la protección de los defensores y defensoras ambientales
}

\section{The right to defend the environment: The protection of the environmental defenders}

\section{SUSANA BORRÁS*}

Resumen: La creciente degradación del medio ambiente y competitividad frente a la explotación de los recursos naturales limitados evidencia no solo graves impactos sobre el medio ambiente, sino también genera importantes impactos sociales. La indefensión a la que se enfrentan las víctimas de la degradación ambiental, como víctimas también de violaciones de derechos humanos, ha dado origen a un movimiento de resistencia liderado por los llamados «defensores ambientales», quienes, más allá del activismo, intentan proteger el medio ambiente y defender a los grupos más vulnerables frente a este tipo de agresiones ambientales. De ahí que hayan proliferado últimamente, y de forma muy preocupante, los abusos contra los derechos humanos de estas personas. La frecuencia de asesinatos y amenazas que sufren los defensores ambientales, la vulneración de los derechos de sus pueblos y la subsiguiente impunidad de los autores de estas graves violaciones genera la necesidad de señalar cuáles son los problemas existentes en la identificación de esta realidad, en su reconocimiento y protección jurídica, y de analizar cuál es la protección y asistencia, que desde el ámbito internacional, se confiere a estas personas en situación de alto riesgo.

Palabras clave: defensores ambientales - medio ambiente - derechos humanos

Summary: The increasing degradation of the environment and competitiveness on the exploitation of the natural limited resources demonstrates not only serious impacts on the environment, but also it generates important social impacts. The defenselessness which the victims of the environmental degradation face, as victims also of violations of human rights, has given origin to a movement of resistance led by the so called «environmental defenders», who, beyond the activism, try to protect the environment and to defend the most vulnerable groups affected by this type of environmental aggressions. This has led to the recent and worrying proliferation of abuses against the human rights of these people. The frequency of murders and threats that the defenders

\footnotetext{
* Profesora de Derecho Internacional Público y Relaciones Internacionales, Universidad Rovira i Virgili (Tarragona-España). Este artículo se ha realizado en el ámbito del proyecto financiado por el Ministerio de Ciencia e Innovación. Convocatoria de ayudas de proyectos de investigación fundamental no orientada titulado «La garantía jurídica de la vertiente intrageneracional de la justicia ambiental como aspecto social del desarrollo sostenible». DER2010-19529. Investigador principal: Dr. Antoni Pigrau Solé. Período 2011-2013. Correo electrónico: susana.borras@urv.net
} 
suffer, the infringement of the rights of its peoples and the subsequent impunity of the authors of these serious violations generate the need to point out the existing problems in the identification of this reality, in its recognition and legal protection and of analyzing which is the protection and assistance, that from the international area, these persons are awarded in situation of high risk.

Key words: environmental defenders - environment - human rights

\begin{abstract}
CONTENIDO: I. INTRODUCCIÓN.- II. LOS DEFENSORES AMBIENTALES Y LA PROTECCIÓN DEL MEDIO AMBIENTE.- III. LA PROTECCIÓN INTERNACIONAL DE LOS DEFENSORES AMBIENTALES.- III.1. LOS INSTRUMENTOS JURÍDICOS INTERNACIONALES PARA DEFENDER A LOS DEFENSORES AMBIENTALES.III.2. LAS RELATORÍAS ESPECIALES SOBRE LA SITUACIÓN DE LOS DEFENSORES DE LOS DERECHOS HUMANOS.- IV. LA PROTECCIÓN DE LOS DEFENSORES AMBIENTALES EN EL SISTEMA INTERAMERICANO DE DERECHOS HUMANOS.V. RESPUESTAS DE LA SOCIEDAD CIVIL: CONSTRUYENDO LA PROTECCIÓN DE LOS DEFENSORES AMBIENTALES.- V.1. EL TRIBUNAL ÉTICO ANTE LA CRIMINALIZACIÓN DE DEFENSORES Y DEFENSORAS DE LA NATURALEZA, EL AGUA Y LA PACHAMAMA.- V.2. FONDOS DE PROTECCIÓN Y DEFENSA.V.3. LA ASISTENCIA LEGAL DE LOS DEFENSORES AMBIENTALES.V.4. PROGRAMAS DE PROTECCIÓN.- VI. REFLEXIONES FINALES.
\end{abstract}

\title{
I. INTRODUCCIÓN
}

La demanda mundial de recursos naturales, que se están agotando, ha provocado una mayor competencia entre las empresas multinacionales. Competencia que a menudo provoca daños sociales y ambientales irreparables y respuestas desmesuradas frente a quienes se oponen, como la criminalización de los defensores ambientales y la violación de sus derechos humanos.

Cuando se habla de las violaciones cometidas contra defensores ambientales se hace referencia a individuos o grupos que son víctimas de violaciones a los derechos humanos debido a su actividad de defensa del medio ambiente, como la gente que se opone a los proyectos destructivos en el sector extractivo, de infraestructura y desarrollo; los derechos de las comunidades indígenas y de las minorías; los derechos de las mujeres, los comunicadores, los abogados y los académicos; o simplemente quienes defienden sus propios derechos a proteger su modo de vida sostenible. Los defensores ambientales son individuos que no necesariamente se identifican como activistas por la justicia ambiental, sino que mediante sus acciones están defendiendo la justicia ambiental o a los pueblos afectados por las injusticias ambientales, ya sea a nivel comunitario, nacional o internacional. 
Los frecuentes asesinatos de y amenazas a los defensores ambientales, la vulneración de los derechos de sus pueblos y la subsiguiente impunidad de los autores de estas graves violaciones afectan la protección del medio ambiente y de los derechos humanos más fundamentales. Las violaciones de los derechos humanos de estos defensores ambientales, generalmente, tienen relación directa con sus actividades de reivindicación, defensa y protección de los territorios y los recursos naturales, la defensa del derecho a la autonomía y el derecho a la identidad cultural.

Este no es un problema limitado a una determinada actividad o a un país particular. Por el contrario, existe una creciente tendencia regional hacia la violencia en contra de defensores ambientales, básicamente promovida por la ausencia del Estado —en cuanto garante de los derechos de las personas-, el cual frecuentemente es corrompido o cooptado por intereses económicos.

El derecho de participación y el derecho de información en los temas ambientales constituyen dos pilares fundamentales para la actividad desarrollada por los defensores ambientales. Estas personas proporcionan información a la sociedad civil que emplaza al Estado a asumir su obligación de garante de los derechos. Los defensores ambientales también organizan a la comunidad para luchar por sus derechos y la justicia ambiental.

Precisamente por estos motivos, los defensores ambientales han sido el blanco de la violencia, porque se han enfrentado a los impactos ambientales de distintas actividades, en especial, los de la industria extractiva. Estos impactos incluyen la contaminación de las aguas, el aire y los suelos, así como la relocalización forzada, la corrupción, y la prostitución y el alcoholismo. Queda en evidencia que los impactos sociales y ambientales afectan a derechos humanos fundamentales, como son el derecho a la vida y al hogar, el derecho al agua y a la comida, el derecho a la propiedad, y el derecho al consentimiento libre, previo e informado.

La omisión del propio Estado de investigar agresiones y crímenes cometidos contra los defensores ambientales facilita el camino a las empresas para continuar denostando y agrediendo a estos y debilitar su rol defensor. Así, una práctica constante de las autoridades en materia ambiental es su mala fe respecto a los denunciantes, al no proporcionar la posibilidad del derecho de queja, favoreciendo a los inversionistas. En muchas ocasiones también la autoridad, en contra de la ley, no reconoce el derecho a impugnar y exigir la revocación de las concesiones y en consecuencia permite la violación de las normas ambientales. Otra tendencia de las autoridades es su falta de diligencia en las denuncias ambientales, basada en el argumento de no contar con

EL DERECHO

A DEFENDER

EL MEDIO

AMBIENTE: LA

PROTECCIÓN DE

LOS DEFENSORES

Y DEFENSORAS

AMBIENTALES

THE RIGHTTO

DEFEND THE

ENVIRONMENT:

THE PROTECTION

OFTHE

ENVIRONMENTAL

DEFENDERS 
presupuesto para ejecutar inspecciones. De manera que es recurrente que los juicios se pierdan en razón de la falta de personalidad de los afectados, menoscabo de pruebas, o el simple retardo injustificado de las autoridades en la resolución del caso, provocando que los daños se causen y que la resolución se dé demasiado tarde. Aunado a ello, de darse una resolución a favor de los afectados, a menudo no hay autoridad que cumpla el fallo. En consecuencia, el sistema judicial favorece la impunidad y se ha convertido en una instancia de encubrimiento de las violaciones de derechos humanos. No se investigan las denuncias, aun cuando se presentan pruebas. Y en casos de denuncias ambientales, fiscales y jueces que han intentado realizar su trabajo de manera correcta son obstaculizados, trasladados y hasta removidos de sus cargos.

Todos estos obstáculos generan que las personas que se oponen a la contaminación ambiental, los defensores ambientales, vivan en un alto estado de indefensión y de inseguridad personal y jurídica.

En este sentido, el presente artículo expone la existencia de la relación innegable entre la protección del medio ambiente y el goce efectivo de los derechos humanos y cómo el trabajo de los defensores ambientales es clave para la promoción de los derechos humanos, a pesar de que su identificación, reconocimiento y protección, como se estudiará más adelante, no esté lo suficientemente desarrollada. Sin duda, el objetivo de este estudio es doble: el primero es el reconocimiento del papel que en la actualidad desempeñan los defensores ambientales como garantes de los derechos de las poblaciones que sufren las consecuencias de la degradación ambiental; y, el segundo es el de reflejar la situación de vulnerabilidad y alto riesgo a la que se enfrentan los defensores del medio ambiente, sufriendo amenazas y violencia de todo tipo, lo que plantea retos en el reconocimiento de su realidad y en el establecimiento de mecanismos de protección, tal y como a continuación pasa a exponerse.

\section{LOS DEFENSORES AMBIENTALES Y LA PROTECCIÓN DEL MEDIO AMBIENTE}

La Declaración sobre el derecho y el deber de los individuos, los grupos y las instituciones de promover y proteger los derechos humanos $y$ las libertades fundamentales universalmente reconocidos, adoptada por las Naciones Unidas en diciembre de 1998, en el marco del quincuagésimo aniversario de la Declaración universal de los derechos 
humanos, establece en su artículo primero que «toda persona tiene derecho, individual o colectivamente, a promover y procurar la protección y realización de los derechos humanos y las libertades fundamentales en los planos nacional e internacional» ${ }^{1}$. Por lo tanto, toda persona que, de cualquier forma, promueva o procure la realización de los derechos humanos y las libertades fundamentales, reconocidos a nivel nacional o internacional, debe ser considerada como defensora de derechos humanos, incluidos los defensores ambientales ${ }^{2}$.

Algunas organizaciones u organismos internacionales de protección a los derechos humanos han adoptado definiciones operativas sobre lo que son los defensores y las defensoras de derechos humanos. Por ejemplo, Amnistía Internacional se refiere a estas personas como aquellas que «a título individual o colectivo intentan promover y proteger la universalidad y la indivisibilidad de todos los derechos humanos» ${ }^{3} \mathrm{y}$ que están «comprometidos con la realización del ideal que proclama la Declaración universal de derechos humanos de liberar a todas las personas del temor y la miseria» ${ }^{4}$.

La Organización Mundial Contra la Tortura también ha definido a los defensores de los derechos humanos como:

Toda persona que corra el riesgo o que sea víctima de represalias, de hostigamiento o de violación de sus derechos a causa de su compromiso, de conformidad con los instrumentos internacionales de protección de derechos humanos, individualmente o en asociación con un tercero, a favor de la promoción y de la puesta en marcha de derechos reconocidos por la Declaración Universal de Derechos Humanos y garantizados por los diferentes instrumentos internacionales ${ }^{5}$.

Asimismo, el Alto Comisionado de las Naciones Unidas para los Derechos Humanos considera que «un defensor de los derechos humanos es toda persona que, individual o colectivamente, promueve y procura la protección y realización de los derechos humanos y las

1 Organización de las Naciones Unidas. Declaración sobre el derecho y el deber de los individuos, los grupos y las instituciones de promover y proteger los derechos humanos y las libertades fundamentales universalmente reconocidos. Resolución Aprobada por la Asamblea General de las Naciones Unidas en su quincuagésimo tercero período de sesiones el 9 de diciembre de 1998 (http:// www.un.org/spanish/aboutun/organs/ga/53/ares53144.pdf), 1999.

2 Ver Comisión Interamericana de Derechos Humanos. Informe sobre la situación de las defensoras y defensores de los derechos humanos en las Américas. OEA/Ser.L/V/II. 124 Doc. 5 rev.1-7 de marzo de 2006, párrafo 13.

3 Amnistía Internacional. Preguntas y respuestas sobre defensores y defensoras de los derechos humanos, (http://www.es.amnesty.org/temas/defensores/preguntas-y-respuestas/), 2013.

4 Amnistía Internacional. Defensores de los derechos humanos en Latinoamérica. Más protección, menos persecución. Madrid: Editorial Amnistía Internacional, 1999, p. 9.

5 Organización Mundial Contra la Tortura. Sobre las actividades defensores de derechos humanos, (http://www.omct.org/es/human-rights-defenders/about/), 2013.

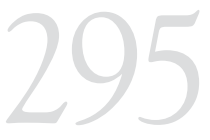

EL DERECHO

A DEFENDER

EL MEDIO

AMBIENTE: LA

PROTECCIÓN DE

LOS DEFENSORES

Y DEFENSORAS

AMBIENTALES

THE RIGHT TO

DEFENDTHE

ENVIRONMENT:

THE PROTECTION

OFTHE

ENVIRONMENTAL

DEFENDERS 
libertades fundamentales, sea en el nivel nacional o en el internacional, sin importar su cargo, función o tarea que cumplan en la sociedad ${ }^{6}$.

Incluso, desde la misma Unión Europea también se conciben a los defensores de los derechos humanos como:

[...] aquellos individuos, grupos y organismos de la sociedad que promueven y protegen los derechos humanos y las libertades fundamentales universalmente reconocidos. Los defensores de los derechos humanos persiguen la promoción y la protección de los derechos civiles y políticos, así como la promoción, la protección y la realización de los derechos económicos, sociales y culturales. Los defensores de los derechos humanos promueven y protegen asimismo los derechos de los miembros de grupos tales como las comunidades indígenas. La definición no incluye a los individuos o grupos que cometan actos violentos o propaguen la violencia?

En este sentido, parece observarse cierta convergencia sobre lo que debe entenderse como defensor/a de los derechos humanos. Este consenso considera la situación de vulnerabilidad a la que se enfrentan los defensores y defensoras de derechos humanos en muchas ocasiones. Es decir, toma en cuenta el riesgo, tanto para los individuos como para los grupos que estos conforman, de ser víctimas de la criminalización de su protesta, desapariciones forzadas, detenciones arbitrarias, torturas, ejecuciones sumarias, entre otras. Acciones realizadas tanto por funcionarios o agentes del Estado así como por instituciones o personas privadas que actúan con permiso o aprobación del propio Estado.

El concepto de defensor/a ambiental parece ciertamente novedoso y no está lo suficientemente definido, si bien comparte el concepto y muchas de las realidades de los defensores de derechos humanos. En todo caso, los defensores ambientales cumplen una trascendental función social, ya que proteger el medio ambiente conlleva también avanzar en la protección de los derechos humanos.

Precisamente, la relación entre protección ambiental y protección de los derechos humanos, que defienden los defensores ambientales,

6 Oficina en Colombia del Alto Comisionado de las Naciones Unidas para los Derechos Humanos. Defensores de derechos humanos. Bogotá: Nuevas Ediciones, 2002, p. 11, (http://www.hchr.org.co/ publicaciones/seriestematicas/Defensores\%20de\%20DH.pdf).

7 Consejo de la Unión Europea. «Proyecto de conclusiones del Consejo sobre las directrices de la Unión Europea sobre defensores de los derechos humanos", 100056/1/04 REV 1, Bruselas, 9 de junio de 2004, puntos 2 y 3 y las directrices de la Unión Europea para la protección de los defensores de los derechos humanos, adoptadas en junio de 2004 y revisadas en 2008 , y las directrices de la Unión Europea en materia de diálogo sobre derechos humanos, adoptadas el 13 de diciembre de 2001 y revisadas en 2009. 
ha sido expresamente reconocida por la reflexión de la señora Hina Jilani, representante especial de Naciones Unidas para los Defensores de derechos humanos. Según la cual, el término defensores de derechos humanos no está restringido exclusivamente a aquellos que promueven y protegen los derechos civiles y políticos. Es decir, según Jilani, se reconoce como defensores de derechos humanos a aquellos que luchan por la promoción, protección, e implementación de los derechos sociales económicos y culturales. En consecuencia, aquellos que defienden el derecho a un medio ambiente sano, o que promueven los derechos de los pueblos indígenas se encuentran sin duda alguna dentro de la definición de defensores de derechos humanos ${ }^{8}$. Además, cualquier actividad pacífica por parte de los defensores destinada a señalar que el Estado no ha creado las condiciones sociales, económicas y políticas requeridas para que las personas puedan disfrutar en la práctica de todos sus derechos y libertades es legítima y está comprendida en el ámbito de la protección que concede la Declaración sobre los defensores de los derechos humanos ${ }^{9}$, adoptada por las Naciones Unidas el 9 de diciembre de $1998^{10}$.

Los defensores ambientales sufren la violación de sus derechos más fundamentales como consecuencia de la existencia de una degradación ambiental previa. La mayoría de los casos, por lo tanto, está relacionado con la degradación ambiental del hábitat de comunidades indígenas y/o pobres. Estos defensores del medio ambiente no siempre son «activistas» o miembros de organizaciones en defensa del medio ambiente, sino que muy frecuentemente son personas que simplemente se enfrentan a decisiones importantes que afectan su medio ambiente, o pueblos indígenas cuyo uso tradicional de sus tierras es amenazado.

En este sentido, la indefensión de las víctimas de degradación ambiental como víctimas de violaciones de derechos humanos provoca que sean principalmente los defensores ambientales quienes intentan defender a los grupos más vulnerables. De ahí que los abusos de derechos humanos de defensores ambientales estén ocurriendo como consecuencia adicional de la violación de otros derechos humanos representados por estos activistas.

Las empresas nacionales y multinacionales, especialmente las dedicadas a la industria extractiva, son las que principalmente han estigmatizado a los defensores ambientales, con la complicidad de las autoridades estatales.

8 ONU. Documento E/CN.4/2001/94 y RuIz, Miriam. «Hina Jilani, primera representante especial de defensores de derechos humanos». Comunicación e Información de la Mujer. Nueva York, 24 de agosto de 2000.

9 Resolución aprobada por la Asamblea General, A/RES/53/144, Declaración sobre los defensores de los derechos humanos, (http://www.unhchr.ch/huridocda/huridoca.nsf/\%28Symbol\%29/A. RES.53.144.Sp?OpenDocument), 1999.

10 Consultar el Informe A/HRC/4/37, párrafos 27- 30.

EL DERECHO

A DEFENDER

EL MEDIO

AMBIENTE: LA

PROTECCIÓN DE

LOS DEFENSORES

Y DEFENSORAS

AMBIENTALES

THE RIGHTTO

DEFENDTHE

ENVIRONMENT:

THE PROTECTION

OFTHE

ENVIRONMENTAL

DEFENDERS 
Las autoridades enjuician a los defensores, atribuyéndoles cargos civiles y penales injustificados, con la pretensión de detener la protesta social y que el movimiento ambientalista se enfoque en la excarcelación de sus líderes. Así, los defensores ambientales se encuentran en una situación particular de doble vulnerabilidad: por enfrentarse a los intereses del propio Estado y a poderosos grupos económicos, que en la mayoría de los casos cuentan con la connivencia del Estado.

\section{LA PROTECCIÓN INTERNACIONAL DE LOS DEFENSORES AMBIENTALES}

El trabajo de defensores y defensoras ha sido recogido y garantizado en diferentes instrumentos adoptados por la comunidad internacional y que integran el denominado corpus juris de los derechos y libertades contenidos en el ordenamiento jurídico internacional de los derechos humanos. En algunos de estos instrumentos jurídicos internacionales se reconoce el derecho a un ambiente sano, directa o indirectamente, sin embargo, no hay ninguno aún que reconozca, expresamente, el derecho a defender el medio ambiente. En realidad, la falta de conciencia, tanto de los organismos internacionales como de la sociedad civil organizada, de que los activistas ambientales son defensores de derechos humanos agudiza seriamente su situación de indefensión.

\section{III.1.Los instrumentos jurídicos internacionales para defender a los defensores ambientales}

De acuerdo con la Declaración universal de los derechos humanos ${ }^{11}$, de 10 de diciembre de 1948, toda persona tiene derecho a un recurso efectivo ante los tribunales nacionales competentes que la ampare contra actos que violen sus derechos fundamentales reconocidos por la constitución o por la ley (artículo 8). En este sentido, nadie podrá ser arbitrariamente detenido, preso ni desterrado (artículo 9) y toda persona, según su artículo 10, tiene derecho, en condiciones de plena igualdad, a ser oída públicamente y con justicia por un tribunal independiente e imparcial, para la determinación de sus derechos y obligaciones o para el examen de cualquier acusación contra ella en materia penal. Asimismo, toda persona acusada de delito tiene derecho a que se presuma su inocencia mientras no se pruebe su culpabilidad, conforme a la ley y en juicio público en el que se le hayan asegurado todas las garantías necesarias para su defensa (artículo 11). En sus artículos 19, 20 y 28 se proclaman los derechos básicos de quienes defienden los derechos humanos: respectivamente, el derecho a la libertad de opinión y de expresión, el derecho a la libertad de reunión

11 Adoptada y proclamada por la resolución de la Asamblea General 217 A (III) del 10 de diciembre de 1948, (http://www.un.org/es/documents/udhr/). 
y de asociación pacíficas, y el derecho al establecimiento de un orden social e internacional en el que los derechos y libertades proclamados en ella se hagan plenamente efectivos.

El Pacto internacional de derechos económicos, sociales y culturales y el Pacto internacional de derechos civiles y políticos comparten un mismo artículo 1 , en el que, entre otras cosas, se dispone que:

Para el logro de sus fines, todos los pueblos pueden disponer libremente de sus riquezas y recursos naturales, sin perjuicio de las obligaciones que derivan de la cooperación económica internacional basada en el principio de beneficio recíproco, así como del Derecho internacional. En ningún caso podrá privarse a un pueblo de sus propios medios de subsistencia.

Este párrafo se suma a lo dispuesto en el artículo 17 de la Declaración universal de derechos humanos sobre el derecho a la propiedad.

La Convención americana de derechos humanos ${ }^{12}$, reconociendo que «solo puede realizarse el ideal del ser humano libre, exento del temor y de la miseria, si se crean condiciones que permitan a cada persona gozar de sus derechos económicos, sociales y culturales, tanto como de sus derechos civiles y políticos», ha establecido, en su artículo 8, que toda persona tiene derecho a ser oída, con las debidas garantías y dentro de un plazo razonable, por un juez o tribunal competente, independiente e imparcial, establecido con anterioridad por la ley, en la sustanciación de cualquier acusación penal formulada contra ella, o para la determinación de sus derechos y obligaciones de orden civil, laboral, fiscal o de cualquier otro carácter.

El derecho de las defensoras y defensores a participar en actividades de protección y promoción de un medio ambiente sano ha sido reconocido por la Asamblea General de la ONU, desde 1982, en la Carta mundial de la naturaleza, la cual reconoce que toda persona «tendrá la oportunidad de participar, individual o colectivamente en la preparación de las decisiones que conciernan directamente a su medio ambiente, y cuando este haya sido objeto de daño o deterioro, podrá ejercer los recursos necesarios para obtener una indemnización» ${ }^{13}$. Asimismo, en el ámbito internacional, el Programa Agenda 21 de la Conferencia de Naciones Unidas sobre el Medio Ambiente y el Desarrollo reconoció la

12 La convención fue adoptada en la Conferencia especializada interamericana sobre derechos humanos, San José, Costa Rica, noviembre de 1969. Serie sobre Tratados OEA número 36, (http://www.oas.org/juridico/spanish/tratados/b-32.html). Veinticinco Estados han ratificado o se han adherido a la Convención: Argentina, Barbados, Bolivia, Brasil, Colombia, Costa Rica, Chile, Dominica, Ecuador, El Salvador, Grenada, Guatemala, Haití, Honduras, Jamaica, México, Nicaragua, Panamá, Paraguay, Perú, República Dominicana, Surinam, Trinidad y Tobago, Uruguay y Venezuela. Aunque Trinidad y Tobago abandonó la Convención Americana sobre Derechos Humanos en 1998. 13 Asamblea General de la ONU, Resolución 37/7, Carta mundial de la naturaleza, (http://www.pnuma. org/docamb/cn1982.php), 1982, principio 23.

EL DERECHO A DEFENDER

EL MEDIO

AMBIENTE: LA

PROTECCIÓN DE

LOS DEFENSORES

Y DEFENSORAS

AMBIENTALES

THE RIGHT TO

DEFEND THE

ENVIRONMENT:

THE PROTECTION

OFTHE

ENVIRONMENTAL

DEFENDERS 
importancia de la cooperación entre las organizaciones y los Estados para procurar la conservación del medio ambiente y lograr el desarrollo ${ }^{14}$.

La Declaración sobre los principios fundamentales de justicia para las víctimas de delitos y del abuso de poder de $1985^{15}$ permite determinar la situación de las personas criminalizadas y judicializadas, que han sido primero victimizadas cuando se les han vulnerado sus derechos colectivos y luego re-victimizadas, cuando se les castiga por la reivindicación de sus derechos violados. Esta Declaración establece que «las víctimas serán tratadas con compasión y respeto por su dignidad. Tendrán derecho al acceso a los mecanismos de la justicia y a una pronta reparación del daño que hayan sufrido, según lo dispuesto en la legislación nacional» (artículo 4). Al respecto, la Declaración también se refiere a que se utilizarán, cuando proceda, mecanismos oficiosos para la solución de controversias, incluidos la mediación, el arbitraje y las prácticas de justicia consuetudinaria o autóctonas, a fin de facilitar la conciliación y la reparación a favor de las víctimas (artículo 7).

Finalmente, la Declaración, en su artículo 19, se refiere a que los Estados considerarán la posibilidad de incorporar a la legislación nacional normas que proscriban los abusos de poder y proporcionen remedios a las víctimas de esos abusos. En particular, esos remedios incluirán el resarcimiento y la indemnización, así como la asistencia y el apoyo material, médico, psicológico y social necesarios.

En la Declaración y programa de acción de Viena, aprobados por la Conferencia Mundial de Derechos Humanos, del mes de junio de 1993, se menciona a los defensores de derechos humanos, reconociendo la importante función que cumplen las organizaciones no gubernamentales en la promoción de todos los derechos humanos y en las actividades humanitarias a nivel nacional, regional e internacional y considera que deben realizar sus actividades de derechos humanos sin injerencias, en el marco de la legislación nacional y de la Declaración universal de derechos humanos ${ }^{16}$.

Otro fundamento importante para proteger a los defensores ambientales es la Declaración sobre el derecho y el deber de los individuos, los grupos y las instituciones de promover y proteger los derechos humanos y las

\footnotetext{
14 En concreto se refería a que «Los países, en cooperación con las organizaciones nacionales, regionales e internacionales, según procediera, deberían velar por que existieran o se pudieran capacitar los recursos humanos indispensables para proceder a la integración del medio ambiente y el desarrollo en diversas etapas del proceso de adopción de decisiones y de ejecución». Cumbre para la Tierra. Programa de Acción de las Naciones Unidas de Río, Agenda 21, aprobada en Río de Janeiro, (http://www.un.org/esa/dsd/agenda21_spanish/res_agenda21_08.shtml), 1992, párrafo 8.10 .

15 A/RES/40/34, 29 de noviembre de 1985, (http://daccess-dds-ny.un.org/doc/RESOLUTION/GEN/ NR0/485/21/IMG/NR048521.pdf?OpenElement).

$16 \mathrm{ONU}$. Conferencia Mundial de Derechos Humanos. Declaración y programa de acción de Viena, 1993, «Primera Parte», párrafo 38.
} 
libertades fundamentales universalmente reconocidos ${ }^{17}$, más conocida como Declaración sobre los defensores de los derechos humanos, que fue adoptada por consenso el 9 de diciembre de 1998 en el seno de la Asamblea General de la Organización de las Naciones Unidas ${ }^{18}$. En el preámbulo de esta declaración, se reconoce la legitimidad de las actividades de promoción de los derechos económicos, sociales y culturales al reconocerse «la valiosa labor que llevan a cabo los individuos, los grupos y las instituciones» en la eliminación de las violaciones, incluidas las derivadas de «la negativa a reconocer el derecho de los pueblos a la libre determinación y el derecho de todos los pueblos a ejercer plena soberanía sobre su riqueza y sus recursos naturales». En su anexo se recoge la Declaración sobre el derecho y el deber de los individuos, los grupos y las instituciones de promover y proteger los derechos humanos y las libertades fundamentales universalmente reconocidos ${ }^{19}$, la cual establece que toda persona tiene derecho, individual o colectivamente, a promover y procurar la protección y realización de los derechos humanos y las libertades fundamentales en los planos nacional e internacional (artículo 1). A fin de promover y proteger los derechos humanos y las libertades fundamentales, de acuerdo con su artículo 5, toda persona tiene derecho, individual o colectivamente, en el plano nacional e internacional: $a$ ) a reunirse o manifestarse pacíficamente; $b$ ) a formar organizaciones, asociaciones o grupos no gubernamentales, y a afiliarse a ellos o a participar en ellos; c) a comunicarse con las organizaciones no gubernamentales e intergubernamentales. Y el artículo 9 reconoce que toda persona tiene derecho, individual o colectivamente, entre otras cosas, a denunciar las políticas y acciones de los funcionarios y órganos gubernamentales en relación con violaciones de los derechos humanos $\mathrm{y}$ las libertades fundamentales mediante peticiones $\mathrm{u}$ otros medios adecuados ante las autoridades judiciales, administrativas o legislativas internas o ante cualquier otra autoridad competente prevista en el sistema jurídico del Estado, las cuales deben emitir su decisión sobre la denuncia sin demora indebida.

En este sentido, la protección que se concede a los defensores en dicha declaración no depende de si la labor principal de los defensores de que se trata se centra en derechos civiles y políticos o en derechos económicos, sociales y culturales. Cualquier actividad pacífica por parte de los defensores destinada a señalar que el Estado no ha creado las condiciones sociales, económicas y políticas requeridas para que

\footnotetext{
17 Resolución A/RES/53/144.

18 La declaración sobre defensores y defensoras de los derechos humanos comenzó a elaborarse en el año 1984. La Comisión de Derechos Humanos de la Organización de las Naciones Unidas estableció un grupo de trabajo en el año 1985 encargado de la redacción de una declaración sobre El derecho y el deber de los individuos, los grupos y las instituciones de promover y proteger los derechos humanos. El grupo de trabajo estuvo compuesto por gobiernos y se permitió la participación de organizaciones civiles, quienes tardaron trece años antes de tener un texto para la aprobación final. 19 Declaración sobre los defensores de los derechos humanos.
}

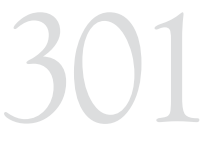

EL DERECHO

A DEFENDER

EL MEDIO

AMBIENTE: LA

PROTECCIÓN DE

LOS DEFENSORES

Y DEFENSORAS

AMBIENTALES

THE RIGHT TO

DEFEND THE

ENVIRONMENT:

THE PROTECTION

OF THE

ENVIRONMENTAL

DEFENDERS 
las personas puedan disfrutar en la práctica de todos sus derechos y libertades es legítima y está comprendida en el ámbito de la protección que concede dicha declaración ${ }^{20}$.

Finalmente, es preciso subrayar la importancia de las Directrices de la Unión Europea sobre defensores de los derechos humanos ${ }^{21}$, adoptadas en 2004 y revisadas en 2008, como parte de los instrumentos internacionales no convencionales que han permitido operativizar varias iniciativas de los países de la Unión Europea para la defensa y protección de los defensores y defensoras de derechos humanos. Estas directrices fueron adoptadas por el Consejo de la Unión Europea el 15 de junio de 2004 y constituyen principios generales y orientadores de la conducta de los Estados de la Unión Europea, sobre la defensa y protección a defensores y defensoras de derechos humanos, no solo en el continente europeo sino en el ámbito global. Todas ellas son sugerencias prácticas que deben ser utilizadas para la buena actuación de los países de la Unión Europea en el apoyo a los defensores y defensoras de derechos humanos y de esta forma fortalecer su trabajo encaminado a defender los derechos humanos. A su vez, también pretenden influir para que terceros países cumplan sus obligaciones de respetar los derechos de los defensores de los derechos humanos y protegerles de los ataques y amenazas de agentes no estatales ${ }^{22}$.

En unámbito internacional, pero nogubernamental, es de interés referirse a la protección de los defensores ambientales en el documento de la Declaración de Cartagena, que se adoptó en la Conferencia Internacional de Derechos Ambientales y Derechos Humanos, celebrada entre el 16 y el 18 de septiembre de 2003 en Cartagena, Colombia y convocada por Amigos de la Tierra Internacional, Transnational Institute y la red Oil Watch ${ }^{23}$. Esta declaración defiende la seguridad con el fin de que no se siga criminalizando ni persiguiendo a los defensores de derechos

20 Ver el reporte presentado ante el Consejo para los Derechos Humanos (Human Rights Council) en marzo de 2006 por la Representante Especial para los Defensores de Derechos Humanos: JILANI, Hina. «Implementation of General Assembly Resolution 60/251», A/HRC/4/37, (http://daccessdds-ny.un.org/doc/UNDOC/GEN/G07/104/17/PDF/G0710417.pdf?OpenElement), 2007, párrafos 27-30.

21 Consejo de la Unión Europea. «Proyecto de conclusiones del Consejo sobre las directrices de la Unión Europea sobre defensores de los derechos humanos".

22 También consultar otros documentos relacionados, como la resolución del Parlamento Europeo, de 17 de junio de 2010, sobre las políticas de la UE en favor de los defensores de los derechos humanos (2009/2199(INI)); el reglamento (CE) número 1889/2006 del Parlamento Europeo y del Consejo, de 20 de diciembre de 2006, por el que se establece un instrumento financiero para la promoción de la democracia y de los derechos humanos a escala mundial (Instrumento Europeo para la Democracia y los Derechos Humanos, DO L 386 de 29.12.2006, p. 1); la resolución, de 25 de abril de 2002, sobre la Comunicación de la Comisión al Consejo y al Parlamento Europeo - El papel de la Unión Europea en el fomento de los derechos humanos y la democratización en terceros países, DO C $131 \mathrm{E}$ de 5 de junio de 2003, p. 147.

23 En la misma participaron doscientos cincuenta delegados de organizaciones ambientalistas, ONGs y movimientos sociales de varias partes del mundo. 
humanos, a los ambientalistas, ni a quienes se manifiestan contra las injusticias y la guerra ${ }^{24}$.

A pesar de que a nivel nacional e internacional se cuente con normas, leyes e instrumentos internacionales de derechos humanos que protegen a los defensores ambientales, la realidad es que muchos han tenido que enfrentarse a actos de hostigamiento, persecución, intimidación y represalias por su actividad o trabajo. Por esto motivo, a falta de un reconocimiento y protección efectivas, se han establecido otros mecanismos institucionales y de vigilancia, como la Relatoría Especial sobre la situación de los defensores de los derechos humanos, con el fin de denunciar y provocar, en consecuencia, un efecto disuasorio de las actuaciones que vulneran los derechos más básicos de quienes defienden los derechos humanos y el medio ambiente.

\section{III.2.Las Relatorías Especiales sobre la situación de los defensores de los derechos humanos}

La gravedad de la situación de las personas y de las organizaciones no gubernamentales en el mundo y el nivel creciente de represalias en contra de los defensores y defensoras constituyeron una de las razones principales por las cuales se aprobó la Declaración sobre defensores y defensoras de los derechos humanos y por las que la Asamblea General decidiera establecer el mandato de un experto sobre los defensores de derechos humanos con el fin de informar al Consejo de Naciones Unidas sobre Derechos Humanos acerca de esta cuestión ${ }^{25}$. El mandato sobre la situación de los defensores de los derechos humanos fue creado en el año 2000 por la Comisión de Derechos Humanos (como un procedimiento especial) para apoyar la aplicación de la declaración de 1998. El mandato también incluye una perspectiva de género en su labor, y crea conciencia sobre la situación de los defensores y las defensoras que corren mayores riesgos y sobre las violaciones cometidas en su contra.

En 2008, mediante la resolución 7/8, y en 2011, con la resolución 16/5, el Consejo de Derechos Humanos decidió prorrogar el mandato sobre los defensores de los derechos humanos por períodos consecutivos de tres años. En marzo de 2008, el Consejo de Derechos Humanos nombró a la señora Margaret Sekaggya relatora especial sobre la situación de los defensores de los derechos humanos.

En sus informes al Consejo de Derechos Humanos de la ONU, tanto la actual como la anterior relatora especial del secretario general de la ONU

24 Para consultar el texto de la declaración consultar en línea el sitio http://wp.cedha.net/wp-content/ uploads/2011/05/Declaraci\%C3\%B3n-de-Cartagena.pdf.

25 Ver la resolución del Consejo de Naciones Unidas sobre Derechos Humanos (Human Rights Council) de 2010 sobre la protección de los defensores de derechos humanos (Resolution on Protection of Human Rights Defenders).

\section{EL DERECHO \\ A DEFENDER \\ EL MEDIO \\ AMBIENTE: LA \\ PROTECCIÓN DE \\ LOS DEFENSORES \\ Y DEFENSORAS \\ AMBIENTALES}

THE RIGHT TO

DEFEND THE

ENVIRONMENT:

THE PROTECTION

OF THE

ENVIRONMENTAL

DEFENDERS 
sobre la situación de los defensores de derechos humanos, Margaret Sekaggya ${ }^{26}$ e Hina Jilani ${ }^{27}$, han enfatizado la particular vulnerabilidad de los defensores de derechos humanos que trabajan defendiendo derechos vinculados a la tierra y recursos naturales.

En efecto, desde su creación y hasta 2007, se ha enviado más de ochenta y un comunicaciones relativas a violaciones de los derechos de defensores que trabajan en defensa de los derechos a la tierra, a los recursos naturales como el petroleo, gas, bosques y agua y otras cuestiones ambientales relativas a la contaminación y vertido de residuos ${ }^{28}$. Así, desde el establecimiento del mandato, la Relatoría ha recibido, y sigue recibiendo, denuncias de amenazas de muerte, hostigamiento y ataques a los defensores de los derechos humanos. Quienes protestan contra el presunto impacto negativo de determinadas actividades empresariales e industriales sobre los derechos humanos de las comunidades locales ${ }^{29}$.

La relatora especial Margaret Sekaggya emitió un informe vinculante a la Asamblea General de Naciones Unidas en agosto de 201030. El informe, centrado en los abusos de derechos contra los defensores, implicaba a organizaciones no gubernamentales y corporaciones. Una de las recomendaciones más significativas del informe es la petición a las empresas para desarrollar políticas nacionales de derechos humanos en cooperación con los defensores, incluyendo la supervisión y mecanismos de responsabilidad en caso de las violaciones de los derechos de defensores de derechos humanos.

Entre diciembre de 2006 y mayo de 2011, la Relatoría recibió una gran cantidad de comunicaciones, alrededor de unas 106, relacionadas con presuntas violaciones cometidas contra defensores y activistas que trabajaban en cuestiones ambientales y relacionadas con la tierra ${ }^{31}$. Según la información recibida, la Relatoría identificó que el grupo de los defensores ambientales era totalmente heterogéneo, incluía a quienes trabajan en cuestiones relacionadas con las industrias extractivas y proyectos de construcción y desarrollo, a quienes trabajan en favor de los derechos de las comunidades indígenas y las minorías, a las defensoras cuyas actividades se relacionan con los derechos ambientales y relativos

26 Informe de Margaret Sekaggya, relatora especial sobre la situación de los defensores de los derechos humanos, documento $\mathrm{A} / \mathrm{HRC} / 19 / 55$, de 21 de diciembre de 2011, Consejo de Derechos Humanos, décimo noveno período de sesiones, tema 3 de la agenda, «Promoción y protección de todos los derechos humanos, civiles, políticos, económicos, sociales y culturales, incluido el derecho al desarrollo", (http://www.ohchr.org/Documents/HRBodies/HRCouncil/RegularSession/Session19/ A-HRC-19-55_sp.pdf).

27 JILANI, Hina. «Implementation of General Assembly Resolution 60/251», A/HRC/4/37.

28 lbídem.

29 Ver Asamblea General de la ONU. «Human Rights Defenders». Documento A/65/223, (http://www2. ohchr.org/english/issues/defenders/docs/A-65-223.pdf), agosto de 2010, párrafos 9-12.

30 Ibidem.

31 La relatora especial sobre la situación de los defensores de los derechos humanos, Margaret Sekaggya, presentó su cuarto informe al Consejo de Derechos Humanos, de conformidad con las resoluciones 7/8 y 16/5 del Consejo. Ver dicho informe, documento A/HRC/19/55. 
a la tierra y a los periodistas que trabajan en cuestiones ambientales y relativas a la tierra. En este sentido, es importante realizar a continuación un breve análisis de estos colectivos que se incluyen en la categoría de defensores ambientales.

\section{a) Los defensores cuyas actividades se relacionan con los derechos ambientales y relativos a la tierra en el contexto de las actividades de las industrias extractivas y de proyectos de construcción y desarrollo} Respecto de este primer grupo, la Relatoría recibió 34 comunicaciones. El principal contexto en que se producían violaciones era en el de las continuas disputas por la tierra, tanto con actores estatales como con actores no estatales, incluidas empresas multinacionales y empresas de seguridad privadas. Las violaciones denunciadas eran resultado de actividades vinculadas a distintas industrias extractivas y proyectos de construcción y desarrollo, entre ellos plantas hidroeléctricas y fábricas de cemento (Guatemala, Brasil); presas (Brasil, India); vertederos (México); gasoductos (Brasil); enclaves de acceso restringido y puertos deportivos (Bahamas); complejos residenciales y de recreo (México); explotaciones mineras (China, México, Ecuador, Papua Nueva Guinea, Perú); centrales nucleares (Filipinas); producción de crudo y petróleo (China, Nigeria, Perú); y sector maderero (Brasil, Camboya, Honduras, México) $^{32}$.

\section{b) Los defensores que trabajan en favor de los derechos de las comunidades indígenas y las minorías}

Respecto de estos defensores, la Relatoría ha recibido denuncias de violaciones contra defensores que trabajaban en cuestiones ambientales y relativas a la tierra en el contexto de las comunidades indígenas y las minorías, y ha adoptado medidas al respecto ( 29 comunicaciones).

Las actividades realizadas por estos defensores incluían participar en negociaciones con las autoridades locales para resolver conflictos de tierras (Brasil, Colombia y Guatemala) e investigar casos de apropiación de tierras (Bangladesh); defender los derechos de las comunidades indígenas (Estado Plurinacional de Bolivia, Camboya, Guatemala, India, Nueva Zelandia, Perú) y representar a estas comunidades a nivel local y nacional (Bangladesh, Chile, Guatemala, Malasia, México, Perú y Tanzania); hacer campaña contra los desalojos forzosos (México, Colombia); participar en protestas (Chile, India, Nepal); concienciar en el extranjero sobre las violaciones de los derechos humanos cometidas (Papua, Nueva Guinea); hacer campaña en favor de la protección de las fronteras de las reservas naturales (Brasil); y presentar información

EL DERECHO

A DEFENDER

EL MEDIO

AMBIENTE: LA

PROTECCIÓN DE

LOS DEFENSORES

Y DEFENSORAS

AMBIENTALES

THE RIGHT TO

DEFEND THE

ENVIRONMENT:

THE PROTECTION

OF THE

ENVIRONMENTAL

DEFENDERS 
a los mecanismos de derechos humanos de las Naciones Unidas (Guatemala) ${ }^{33}$.

c) Las defensoras que trabajan en cuestiones ambientales y relativas a la tierra

Las defensoras de los derechos humanos que trabajan en cuestiones ambientales y relativas a la tierra también han sido objeto de especial atención por la Relatoría, tras haber enviado diversas comunicaciones (25), entre diciembre de 2006 y mayo de 2011, a América (17), Asia y el Pacífico (6) y África (2).

Según el informe de la relatora, estas defensoras participaron activamente en negociaciones con las comunidades locales para resolver conflictos de tierras (novecientas mujeres en el Brasil, Colombia, Guatemala y la India) y denunciar apropiaciones de tierras (China); tratar de obtener reparación para los pueblos indígenas (India, Nepal, Perú) y denunciar injerencias en sus derechos sobre las tierras (India, Nepal); organizar actos en las comunidades (Colombia); hacer campaña contra las centrales nucleares (Filipinas); hacer campaña contra la creación de enclaves de acceso restringido y puertos deportivos (Bahamas); defender los derechos de los trabajadores del campo (Honduras); protestar contra la creación de un complejo residencial y de recreo (México); rodar un documental sobre los efectos dañinos de la producción de petróleo (Nigeria); hacer campaña en favor de los derechos sobre el agua y en contra de la construcción de una presa (India); y oponerse a proyectos mineros (Perú) ${ }^{34}$.

\section{d) Los periodistas que trabajan en cuestiones ambientales y relativas a la tierra}

Este colectivo es especialmente vulnerable y se expone a sufrir violaciones de sus derechos como consecuencia de una alteración ambiental. Las comunicaciones enviadas en relación con este grupo, un total de nueve, ponen de manifiesto que entre las actividades realizadas por sus integrantes figuraban las siguientes: presentar y producir programas televisados de noticias sobre cuestiones relacionadas con la tierra para expresar preocupación por la relación existente entre la policía nacional y los grupos de seguridad privada (Honduras); informar sobre desalojos forzosos (Uganda); escribir sobre cuestiones ambientales (China, El Salvador, República Islámica del Irán y Federación de Rusia); informar sobre la labor de las empresas mineras (México); documentar en vídeo manifestaciones sobre cuestiones ambientales y relativas a la tierra (Nigeria); e informar sobre la exhumación de cadáveres (Guatemala) ${ }^{35}$. 
En todos los casos anteriormente expuestos, ya sean periodistas, defensores de los derechos de las minorías u otros, hay en común una misma realidad: los defensores ambientales están expuestos a atentados contra su integridad física, como por ejemplo, a sufrir intentos de asesinato, ser asesinados, ser atacados, ser agredidos y maltratados, ser víctimas de un uso excesivo de la fuerza por parte de la policía durante manifestaciones o sufrir malos tratos en centros penitenciarios. Estas personas también han sufrido atentados contra la integridad psicológica en forma de amenazas, entre ellas amenazas de muerte y distintas formas de intimidación y acoso.

En su gran mayoría, los defensores ambientales han sido víctimas de desalojos forzosos, de redadas en sus casas y además han sufrido detenciones y encarcelamientos. Se han criminalizado sus acciones con acusaciones de posesión ilegal de armas, apropiación de tierras y delitos relacionados con el terrorismo. Los autores de estas violaciones son actores tanto estatales como no estatales. Entre los actores estatales figuran la policía, autoridades locales y funcionarios públicos que se han manifestado públicamente en contra de la labor realizada por estos defensores. Entre los actores no estatales figuran empresas trasnacionales, medios de comunicación, grupos paramilitares y guardias privados de seguridad.

Si bien estas violaciones se extienden a todas las regiones del mundo, América parece ser la región en la que estos defensores corren más riesgos, tal y como ha reconocido la misma relatora especial Margaret Sekaggya $^{36}$. Por este motivo, resulta de especial interés analizar cómo se ha canalizado, con cierto éxito, la protección de los defensores ambientales en el sistema Interamericano de Derechos Humanos.

\section{LA PROTECCIÓN DE LOS DEFENSORES AMBIENTALES EN EL SISTEMA INTERAMERICANO DE DERECHOS HUMANOS}

En el ámbito del sistema interamericano, el artículo 11 del Protocolo adicional a la convención americana sobre derechos humanos en materia de derechos económicos, sociales y culturales, Protocolo de San Salvador, reconoce expresamente el derecho de toda persona a «vivir en un ambiente sano y a contar con servicios públicos básicos» ${ }^{37}$. En este

36 Ibídem, párrafo 123.

37 A pesar de que la Declaración americana de los derechos y deberes del hombre y la Convención americana sobre derechos humanos no incluyen referencias expresas a la protección del medio ambiente, la $\mathrm{CIDH}$ ha señalado que varios derechos de rango fundamental requieren como precondición necesaria para su ejercicio la existencia de un medio ambiente sano, y se ven afectados profundamente por la degradación de los recursos naturales. La Comisión ha entendido que tanto la Declaración como la Convención americanas reflejan una preocupación prioritaria por la preservación de la salud y el bienestar del individuo, bienes jurídicos protegidos por la interrelación entre los derechos a la vida, la seguridad de la persona, la integridad física, psíquica y moral, y en esa

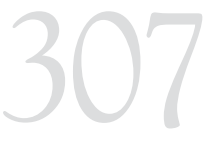

EL DERECHO

A DEFENDER

EL MEDIO

AMBIENTE: LA

PROTECCIÓN DE

LOS DEFENSORES

Y DEFENSORAS

AMBIENTALES

THE RIGHTTO

DEFENDTHE

ENVIRONMENT:

THE PROTECTION

OFTHE

ENVIRONMENTAL

DEFENDERS 
sentido, la Comisión Interamericana de Derechos Humanos (en adelante, Comisión o $\mathrm{CIDH}$ ) ha observado con especial atención la persecución contra los defensores ambientales, especialmente en lo que se refiere al vínculo existente entre el medio ambiente, los defensores y defensoras y los derechos humanos ${ }^{38}$. Asimismo, se ha pronunciado sobre diversas peticiones ${ }^{39}$ y solicitudes de medidas cautelares ${ }^{40}$ enfocadas en la protección de defensoras y defensores que procuran un medio ambiente sano.

Ya en su Informe Anual del año 1998, la Comisión destacó la importancia ética del trabajo y actividades de los defensores y defensoras, quienes llevan adelante la promoción y defensa de los derechos humanos. Dicho informe contiene recomendaciones para los Estados miembros de la Organización de Estados Americanos (OEA) en el sentido de que se tomen todas las medidas necesarias para la protección de la integridad física de defensores y defensoras de derechos humanos y se propicien las condiciones para que desarrollen su labor ${ }^{41}$.

medida refieren al derecho a un medio ambiente sano (ver $\mathrm{CIDH}$. Derechos de los pueblos indígenas y tribales sobre sus tierras ancestrales y recursos naturales. Normas y jurisprudencia del sistema interamericano de derechos humanos, 2009, párrafos 190-191).

38 Ver CIDH. Informe número 69/04 (admisibilidad), Petición 504/03, Comunidad de San Mateo Huanchor y sus miembros, Perú, 15 de octubre de 2004; Informe número 76/09 (admisibilidad), Petición 1473-06, Comunidad de La Oroya, Perú, 5 de agosto de 2009.

$39 \mathrm{CIDH}$. Informe número 11/04 (admisibilidad), Petición 735/01, Teodoro García Cabrera y Rodolfo Montiel Flores, México, 27 de febrero de 2004; Demanda de la Comisión Interamericana de Derechos Humanos, Teodoro Cabrera y Rodolfo Montiel Flores vs. México, 24 de junio de 2009; Informe 67/05 (Admisibilidad), Petición 61/03 Blanca Jeanette Kawas Fernández, Honduras, 13 de octubre de 2005; Demanda de la Comisión Interamericana de Derechos Humanos, Blanca Jeanette Kawas Fernandez vs. Honduras, 4 de febrero de 2008; Informe número 63/04 (admisibilidad), Petición 60/2003, Carlos Antonio Luna, Honduras, 13 de octubre de 2004; Informe número 58/06 (admisibilidad), Petición 1083/05, Erwin Haroldo Ochoa López y Julio Armando Vásquez Ramírez, Guatemala, 20 de julio de 2006; Informe número 80/07 (fondo), Caso 11.658, Martín Pelicó Coxic, Guatemala. Ver también $\mathrm{CIDH}$. Informe sobre la situación de las defensoras y defensores de los derechos humanos en las Américas. OEA/Ser.L/V/II, documento 66, 31 diciembre 2011, párrafo 220.

40 Por ejemplo: medida cautelar 240/09 - Mauricio Meza, Colombia; medida cautelar 239/09 - Héctor Antonio García Berríos y otros, El Salvador; medida cautelar 196/09 - Ampliación de Medidas Cautelares, Honduras - Andrés Tamayo.

41 «Recomendación 4. La Comisión recomienda a los Estados miembros que tomen las medidas necesarias para proteger la integridad física de los defensores de los derechos humanos y propiciar las condiciones para que desarrollen su labor. La Comisión no puede dejar de destacar la importancia y la dimensión ética del trabajo que llevan a cabo las personas dedicadas a la promoción, seguimiento y defensa legal de los derechos humanos y de las organizaciones a las que muchos de ellos se encuentran afiliados. Se trata de personas e instituciones que como parte de la sociedad civil, cumplen un papel crucial en el proceso de control de las instituciones democráticas. Las Naciones Unidas, consciente de la importancia de esta labor, han aprobado la "Declaración sobre el derecho y el deber de los individuos, los grupos las instituciones, de promover y proteger los derechos humanos y las libertades fundamentales universalmente reconocidos". Este instrumento dispone que toda persona tiene derecho, individual o colectivamente, a promover la protección de los derechos humanos y las libertades fundamentales en el plano tanto nacional como internacional. A esos efectos, las personas tienen derecho a reunirse pacíficamente, formar organizaciones no gubernamentales y participar en ellas, así como a formular denuncias relativas a las políticas o los actos de los agentes del Estado en relación con violaciones de los derechos humanos. Periódicamente, la Comisión toma conocimiento de actos de amedrentamiento y atentados, muchas veces fatales, perpetrados contra personas y organizaciones que llevan adelante esta tarea en los Estados miembros. Lamentablemente, durante 1998 estos actos han tenido como víctimas a personas de destacada labor en defensa de los derechos humanos tanto a nivel nacional como internacional. Consecuentemente, la Comisión recomienda a los Estados miembros que promuevan los principios establecidos en la Declaración aprobada por los órganos de las Naciones Unidas y tomen las medidas necesarias para que se respete la libertad de expresión de quienes han asumido la tarea de trabajar para el respeto de los 
Dichas recomendaciones dieron lugar a que la Asamblea General de la OEA adoptara la resolución 1671, denominada Defensores de derechos humanos en las Américas: apoyo a las tareas que desarrollan las personas, grupos y organizaciones de la sociedad civil para la promoción y protección de los derechos humanos en las Américas. En el año 2001, la Asamblea General solicitó a la Comisión, que considerara la elaboración de un estudio sobre la materia y en diciembre de ese mismo año, la Secretaría Ejecutiva estableció una Unidad de Defensores y Defensoras de Derechos Humanos, con el fin de dar seguimiento a la situación de defensores y defensoras en la región americana. Durante el centésimo cuadragésimo primer período de sesiones celebrado en marzo de 2011, la $\mathrm{CIDH}$ decidió crear una Relatoría Sobre la Situación de las Defensoras y los Defensores de Derechos Humanos, en consideración con las denuncias recibidas y en busca de dar mayor visibilidad a la importancia del rol de las defensoras y los defensores y a los operadores de justicia ${ }^{42}$.

En este contexto, la Comisión observa que el rol que las defensoras y defensores cumplen es esencial para garantizar el equilibrio entre la protección ambiental y el desarrollo de los países de la región. Asimismo, su rol es esencial para garantizar el goce de derechos como la vida e integridad personal de los seres humanos ante la exposición a agentes contaminantes que, provenientes de diversas fuentes, pueden afectar la calidad del aire, agua, suelo y subsuelo y perjudicar el goce de los derechos humanos.

Según informaciones de la misma Comisión, los asesinatos y otras violaciones sufridas por las defensoras y defensores ambientales demuestran una tendencia regional en el contexto de la industria extractiva. Esta no se limita tan solo a la minería, sino que se extiende también a otros ámbitos como el de explotación maderera de los bosques. En este sentido, la Comisión ha recibido información que indica que en Brasil cuando menos 125 activistas y líderes campesinos estarían amenazados de muerte y en tan solo cinco días (del 24 al 28 de mayo de 2011) perdieron la vida cuatro personas relacionadas con actividades de defensa del medio ambiente ${ }^{43}$. En El Salvador tan solo entre junio y diciembre de 2009, tres defensores que se oponían

derechos fundamentales, y para que se proteja su vida e integridad personal» (CIDH. Informe Anual 1998. Washington D.C.: CIDH, 1998, recomendaciones del «Capítulo II»).

$42 \mathrm{CIDH}$. «Relatoría sobre Defensoras y Defensores de Derechos Humanos», (http://www.oas.org/es/ cidh/defensores/default.asp).

43 Comissão Pastoral da Terra (CPT). «CPT acaba de enviar à ministra Maria do Rosário novas ameaças contra defensores dos direitos humanos», 7 de junio de 2011, (http://www.cptnacional. org.br/index.php?option=com_content\&view=article\&id=664:cpt-acaba-de-enviar-a-ministra-mariado-rosario-novas-ameacas-contra-defensores-dos-direitos-humanos\&catid=12: $\operatorname{conflitos\& ltemid=54);~}$ Aministía Internacional. «Las autoridades deben actuar para detener muertes en el Amazonas», 2 de junio de 2006, (http://www.amnistia.org.pe/2011/06/02/las-autoridades-deben-actuar-para-detenerlas-muertes-en-el-amazonas/).

EL DERECHO

A DEFENDER

EL MEDIO

AMBIENTE: LA

PROTECCIÓN DE

LOS DEFENSORES

Y DEFENSORAS

AMBIENTALES

THE RIGHTTO

DEFENDTHE

ENVIRONMENT:

THE PROTECTION

OFTHE

ENVIRONMENTAL

DEFENDERS 
a las industrias mineras fueron asesinados ${ }^{44} \mathrm{y}$ uno más fue asesinado en $2011^{45}$. En Guatemala cuatro defensores que procuran un medio ambiente sano habrían perdido la vida en tan solo un mes (enero a febrero de 2010) ${ }^{46}$. En México, durante el período de 2006 a 2012, habrían sido asesinadas cuando menos doce personas, que incluyen tanto funcionarios públicos como personas civiles, defensoras del derecho al medio ambiente.

Sobre la base de la información recibida, la Comisión ha tramitado denuncias de violaciones a los derechos humanos de líderes de comunidades afrodescendientes en varios países de la región y ha solicitado a la Corte Interamericana de Derechos Humanos (en adelante, Corte IDH) la protección de líderes afrodescendientes amenazados ${ }^{47}$. Uno de los casos importantes fue presentado el 4 de febrero de 2008, de conformidad con lo dispuesto en los artículos 51 y 61 de la Convención americana, la Comisión sometió a la Corte una demanda en contra de la República de Honduras, la cual se basó en la denuncia presentada el 13 de enero de 2003 por el Centro por la Justicia y el Derecho Internacional y el Equipo de Reflexión, Investigación y Comunicación de la Compañía de Jesús en Honduras.

El caso se fundamenta en el asesinato de Blanca Jeannette Kawas Fernández, asesinada por un disparo de arma de fuego mientras se encontraba en su residencia. La señora Kawas Fernández era presidenta de la Fundación para la Protección de Lancetilla, Punta Sal, Punta Izopo y Texiguat (en adelante PROLANSATE), organización creada con el objeto de «mejorar la calidad de vida de los pobladores de las cuencas hidrográficas de la Bahía de Tela, (Departamento de Atlántida, Honduras)». En razón de su condición, la señora Kawas denunció, entre otras cosas, los intentos de personas y entidades privadas de apoderarse ilegalmente de la península de Punta Sal, la contaminación de las lagunas y la degradación de los bosques de la región. Tras su muerte se constataron graves omisiones que demuestran que las autoridades estatales no actuaron con la debida diligencia, puesto que no adoptaron todas las medidas que eran necesarias para impulsar una investigación

44 Marcelo Rivera Moreno, de 37 años, miembro de la Asociación Amigos de San Isidro Cabañas (ASIC) activista contra las operaciones de la mina El Dorado; Ramiro Rivera Gómez, de 53 años, miembro del Comité Ambiental de Cabañas (CAC); Dora Alicia Sorto, de 32 años, y también integrante del CAC. Agencia Prensa Rural. «El Salvador: Activistas antiminería y defensores del medio ambiente asesinados», 5 de febrero de 2010, (http://www.prensarural.org/spip/spip.php?breve2122).

$45 \mathrm{CIDH}$. «Comunicado de Prensa 62/11. CIDH condena asesinato de defensor de derechos humanos en El Salvador», Washington D.C., 24 de junio de 2011; Video de la audiencia de la CIDH. «Riesgo para defensores y defensoras ambientales en Mesoamérica», celebrada durante el centésimo cuadragésimo período ordinario de sesiones, el 25 de octubre de 2010.

46 Federación Internacional de los Derechos Humanos (FIDH). «Ola de Asesinatos de defensores de derechos humanos en Guatemala», 22 de febrero de 2010, (http://www.fidh.org/Ola-de-asesinatosde-defensores-de).

47 Corte IDH. Caso de las comunidades del Jiguamiandó y del Curbaradó. Medidas provisionales. Resolución de 6 de marzo de 2003. 
que pudiera llegar a un resultado concreto. Como consecuencia del incumplimiento estatal de sus deberes, se ha negado el derecho de los familiares de la víctima a conocer la verdad sobre lo sucedido y a que se reparen los daños y perjuicios sufridos.

Según la $\mathrm{CIDH}$, «del material que obra en el expediente, puede establecerse que efectivamente se presentan fuertes indicios para concluir que existe responsabilidad estatal directa en la privación de la vida de la presunta víctima» ${ }^{48}$. Consecuentemente, el 13 de octubre de 2005 la Comisión aprobó el Informe número 67/05, mediante el cual declaró admisible la petición. Posteriormente, el 20 de julio de 2006 la Comisión aprobó el Informe de Fondo número 63/06, en los términos del artículo 50 de la Convención, el cual contenía determinadas recomendaciones para el Estado.

Este informe fue notificado al Estado el 4 de agosto de 2006. Tras considerar la información aportada por las partes con posterioridad a la adopción del Informe de Fondo, y ante «la falta de avances sustantivos en el efectivo cumplimiento de [sus recomendaciones]», la Comisión decidió someter el presente caso a la jurisdicción de la Corte.

La Comisión alegó que «los efectos causados por la impunidad del caso y la falta de adopción de medidas que eviten la repetición de los hechos ha alimentado un contexto de impunidad de los actos de violencia cometidos en contra de las defensoras y defensores de derechos humanos y del medio ambiente y los recursos naturales en Honduras». En este sentido, señaló que «el caso refleja la situación de los defensores del medio ambiente y los recursos naturales en Honduras, los ataques en contra de tales personas, y los obstáculos en la investigación de los actos de hostigamiento y persecución». Asimismo, la Comisión consideró que «no existe mérito independiente para declarar responsabilidad estatal respecto de las alegadas violaciones al [derecho a la integridad personal] artículo 5 de la Convención Americana». Consecuentemente, solicitó a la Corte que declarase la responsabilidad internacional del Estado por la violación de todas estas disposiciones.

Los representantes de la víctima presentaron su escrito de solicitudes, argumentos y pruebas, en los términos del artículo 23 del Reglamento. En dicho escrito alegaron que Blanca Jeannette Kawas fue una destacada defensora ambientalista hondureña que promovió la protección de los recursos naturales en su país, principalmente en Tela, zona ubicada en la costa atlántica de Honduras y que, en esa condición, fue asesinada el 6 de febrero de 1995. Los representantes reiteraron que la muerte

EL DERECHO

A DEFENDER

EL MEDIO

AMBIENTE: LA

PROTECCIÓN DE

LOS DEFENSORES

Y DEFENSORAS

AMBIENTALES

THE RIGHT TO

DEFEND THE

ENVIRONMENT:

THE PROTECTION

OFTHE

ENVIRONMENTAL

DEFENDERS 
de la señora Kawas Fernández «reviste un especial simbolismo, pues es la primera persona asesinada en Honduras por defender los recursos naturales y el ambiente. Tras su ejecución, y por la impunidad que la caracterizó, se sucedieron una serie de asesinatos contra otros defensores ambientalistas en Honduras».

Así, los representantes solicitaron a la Corte la responsabilidad del Estado por la violación del artículo 4 (Derecho a la Vida) de la Convención, en relación con el artículo 1.1 del mismo instrumento, en perjuicio de Blanca Jeannette Kawas Fernández, «por la [supuesta] participación de agentes estatales en ordenar, planificar y ejecutar su asesinato y por la falta de una investigación efectiva de su muerte»; de los artículos 8 (Garantías Judiciales) y 25 (Protección Judicial) de la Convención americana, en relación con el artículo 1.1 del mismo instrumento, en perjuicio de Blanca Jeannette Kawas Fernández y de «sus familiares», "por no haber realizado una investigación seria y efectiva tendiente al procesamiento y sanción de los responsables de la violación del derecho a la vida de Jeannette Kawas»; del artículo 16 (Libertad de Asociación) de la Convención americana, en relación con el artículo 1.1 del mismo instrumento, en perjuicio de Blanca Jeannette Kawas Fernández, «porque la ejecución de la señora Kawas se debió al ejercicio de su derecho a la libertad de asociación», y del artículo 5 (Derecho a la Integridad Personal) de la Convención Americana, en relación con el artículo 1.1 del mismo instrumento, en perjuicio de los «familiares» de Blanca Jeannette Kawas Fernández, «por el sufrimiento causado a raíz de su ejecución y la falta de investigación efectiva».

El Estado rechazó el argumento manifestado por la Comisión, puesto que este caso refleja la situación de los defensores del medio ambiente y los recursos naturales en Honduras, así como los ataques en contra de tales personas y los obstáculos en la investigación de los actos de hostigamiento y persecución contra los mismos. De igual manera, rechazó los argumentos esgrimidos por los representantes, en cuanto que la impunidad del caso Kawas permitió la generación de un contexto de violencia contra los ambientalistas, sin que el Estado asuma eficazmente medidas de prevención e investigación con el agravante de la falta de oficiosidad de los operadores de justicia, favoreciendo un clima de impunidad.

La Corte IDH, en este Caso Kawas Fernández, emitió Sentencia el 3 de abril de $2009^{49}$, concluyendo que el Estado era responsable por la violación del artículo 4 de la Convención americana (Derecho a la Vida), en concordancia con las obligaciones establecidas en el

49 Ver Corte IDH. Caso Kawas Fernández vs. Honduras. Sentencia de 3 de abril de 2009, (Fondo, Reparaciones y Costas). 
artículo 1.1 del mismo tratado, en perjuicio de Blanca Jeannette Kawas Fernández; y de los derechos reconocidos en los artículos 8 (Garantías Judiciales) y 25 (Protección Judicial) de la Convención americana, en conjunción con los artículos 1.1 y 2 de la misma, en perjuicio de los familiares de la señora Kawas Fernández.

En relación con la preservación del medio ambiente, la Corte IDH señala el deber especial de protección que incumbe al Estado cuando se trata de personas que asumen la defensa de derechos humanos. Al respecto, la Corte considera que la violación del deber de garantía, en el que se ha vulnerado el derecho a la vida, contraría la protección general de quienes dedican su vida y su trabajo a la preservación del ambiente, servicio que va mucho allá del derecho particular de alguno o algunos: concierne e interesa a todos. Esta dedicación queda ahora de manifiesto, por cuanto la víctima era una distinguida defensora del ambiente, que por serlo había enfrentado oposiciones y adversidades.

Según la Corte, las acciones y omisiones que lesionan directamente a quienes actúan en este ámbito, intimidan a otras personas que realizan actividades de defensa ambiental en beneficio de la población. La posición de la Corte es la de otorgar especial protección a quienes asumen la defensa de los derechos humanos, entre ellos, la defensa del medio ambiente. En este sentido, la Corte en este caso reconoce que existe una relación innegable entre la protección del medio ambiente y la realización de otros derechos humanos ${ }^{50}$. Por consiguiente, las defensoras y los defensores ambientales se consideran dentro de la categoría de defensoras y defensores de los derechos humanos. De hecho, el trabajo de las defensoras y los defensores ambientales los expone a violaciones de derechos humanos, a esto se refiere la Corte IDH en este caso, cuando se refiere a que «el reconocimiento del trabajo realizado por la defensa del medio ambiente y su relación con los derechos humanos cobra mayor vigencia en los países de la región, en los que se observa un número creciente de denuncias de amenazas, actos de violencia y asesinatos de ambientalistas con motivo de su labor ${ }^{51}$.

La sentencia emitida por la Corte, a modo de reparación, condena al Estado de Honduras por concepto de indemnización a los representantes por daño material e inmaterial, y el reintegro de costas y gastos, según corresponda, dentro del plazo de un año, contado a partir de la notificación del fallo. Asimismo, se determina la necesidad de que el Estado concluya los procedimientos penales, o inicie los

50 Caso de Kawas Fernández c. Honduras, Fondo, reparaciones y costos, Corte IDH, Sentencia de 3 de abril de 2009, Serie C número 196, párrafo 148 (http://www.corteidh.or.cr/docs/casos/articulos/ seriec_196_esp.pdf).

51 Ibídem, nota 3, párrafo 149.

EL DERECHO

A DEFENDER

EL MEDIO

AMBIENTE: LA

PROTECCIÓN DE

LOS DEFENSORES

Y DEFENSORAS

AMBIENTALES

THE RIGHT TO

DEFENDTHE

ENVIRONMENT:

THE PROTECTION

OFTHE

ENVIRONMENTAL

DEFENDERS 
correspondientes, por los hechos que generaron las violaciones del presente caso y resolverlos en los términos que la ley prevea y dentro de un plazo razonable. Establece la obligación del Estado a prestar asistencia psicológica a los familiares de la señora Kawas y, en el plazo de dos años, debe ejecutar una campaña nacional de concienciación y sensibilización sobre la importancia de la labor que realizan los defensores del medio ambiente en Honduras y de sus contribuciones en la defensa de los derechos humanos. Y, finalmente, determina que el Estado debe realizar, en un plazo de un año, un acto público de reconocimiento de responsabilidad internacional.

Otro caso más reciente es el Teodoro Cabrera García y Rodolfo Montiel Flores (Caso 12.449) contra los Estados Unidos Mexicanos ${ }^{52}$. Teodoro Cabrera García y Rodolfo Montiel Flores establecieron en el año 1998, junto con otros campesinos, la Asociación Civil Organización de Campesinos Ecologistas de la Sierra de Petatlán y Coyuca de Catalán (OCESP), para detener las operaciones de tala en los bosques de las montañas de Guerrero, que, en su opinión, amenazan el medio ambiente y el sustento de las comunidades campesinas locales. Ambos fueron víctimas de tratos crueles, inhumanos y degradantes mientras se encontraban detenidos y bajo custodia de miembros del ejército mexicano. Los tratos en cuestión fueron los siguientes: su falta de presentación sin demora ante un juez u otro funcionario autorizado para ejercer funciones judiciales, que controlara la legalidad de la detención; las irregularidades acaecidas en el curso del proceso penal adelantado su contra; la falta de debida diligencia en la investigación y sanción de los responsables de los hechos y en particular la falta de investigación adecuada de las alegaciones de tortura; la falta de reparación adecuada en favor de las víctimas; y la utilización del fuero militar para la investigación y enjuiciamiento de violaciones a los derechos humanos (lo cual constituye una violación a los derechos protegidos por la Convención Americana); incumplimiento de las obligaciones generales de respeto y garantía y de adecuación del ordenamiento interno; e incumplimiento de las obligaciones bajo la Convención contra la Tortura.

El 25 de octubre de 2010 se celebró un audiencia general ante la CIDH sobre la situación de defensores y defensoras del medio ambiente en Mesoamérica ${ }^{53}$, con el fin de denunciar el patrón de violencia en

52 Sentencia de la Corte Interamericana de Derechos Humanos en el caso de Teodoro Cabrera García y Rodolfo Montiel Flores (Caso 12.449) contra los Estados Unidos Mexicanos, de 24 de junio de 2009.

53 Audiencia General del centésimo cuadragésimo período ordinario de sesiones, CIDH. «Situación de defensores y defensoras del medio ambiente en Mesoamérica», octubre de 2010. Ver «Defensoras y defensores ambientales en peligro. Situación de defensores y defensoras del medio ambiente en Mesoamérica». Informe preparado por el Centro para el Derecho Internacional Ambiental para la Audiencia General del 25 de octubre de 2010 durante el centésimo cuadragésimo período ordinario 
contra de las defensoras y los defensores ambientales en el ámbito minero en México y Centroamérica. Defensores ambientales de México, Guatemala, Honduras, El Salvador, y Panamá denuncian la violencia contra los defensores ambientales en el ámbito minero, por dos razones. Primero, en el ámbito minero se han verificado asesinatos, secuestros, torturas, detenciones arbitrarias, y daños a la propiedad privada de defensores ambientales; segundo, los países de la región no cuentan con medidas legislativas adecuadas para asegurar el efectivo goce de los derechos humanos afectados por la industria minera. Por ejemplo, no ha habido procesos encaminados a obtener el consentimiento previo e informado de las comunidades. Asimismo, la fiscalización y monitoreo ambiental, que son esenciales para garantizar el ejercicio de los derechos, es sumamente débil o incluso no existente. Además, no existen mecanismos efectivos para prevenir la contaminación ambiental y para asegurar la distribución equitativa de beneficios.

\section{RESPUESTAS DE LA SOCIEDAD CIVIL: CONSTRUYENDO LA PROTECCIÓN DELOS DEFENSORES AM BIENTALES}

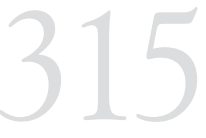

EL DERECHO

A DEFENDER

EL MEDIO

AMBIENTE: LA

PROTECCIÓN DE

LOS DEFENSORES

Y DEFENSORAS

AMBIENTALES

THE RIGHTTO

DEFENDTHE

ENVIRONMENT:

THE PROTECTION

OFTHE

ENVIRONMENTAL

DEFENDERS

A falta de la protección del propio Estado, empiezan a proliferar respuestas y mecanismos de protección de los defensores ambientales desde la sociedad civil. El objetivo de todos ellos es llamar la atención sobre la situación a la que se enfrentan estos colectivos.

De entre los diferentes mecanismos actualmente existentes, es importante destacar los siguientes: la judicialización de las violaciones de los derechos de los defensores ambientales mediante el Tribunal Ético ante la Criminalización de Defensores y Defensoras de la Naturaleza, el Agua y la Pachamama; los fondos de protección y defensa; y la asistencia legal a los defensores ambientales. Estos son solo algunos de los ejemplos de la promoción de la denuncia y protección de estas personas.

\section{V.1. El Tribunal Ético ante la Criminalización de Defensores y Defensoras de la Naturaleza, el Agua y la Pachamama} El Tribunal de los Pueblos contra la Criminalización se organizó en Cuenca, Ecuador, los días 22 y 23 de junio de 2011. El Tribunal fue convocado por las personas, organizaciones, comunidades y pueblos que sufrieron algún tipo de violación de sus derechos fundamentales en razón de la defensa de los derechos colectivos y los de la naturaleza y que fueron llevados —o amenazados con ser llevados— ante instancias 
judiciales penales y administrativas formales bajo diferentes tipos penales, entre ellos, el de terrorismo.

El Tribunal sesionó en el marco del Encuentro Continental por el Agua y la Pachamama, realizado del 21 al 23 de junio en Cuenca, Ecuador, y fue organizado por las asociaciones Acción Ecológica, Red de Ecologistas Populares, Comisión Ecuménica de Derechos Humanos (CEDHU) y la Fundación Regional de Asesoría en Derechos Humanos $(\mathrm{INREDH})^{54}$. El jurado estuvo integrado por Elsie Monge, de Ecuador; Raúl Zibechi, de Uruguay; Lía Isabel Alvear, de Colombia y María Hamlin, de Nicaragua; y los conjueces Raúl Moscoso, Diana Murcia y Carlos Poveda. También fueron invitados como representantes del Estado el procurador general del Estado, el fiscal general de la Nación, el ministro de Justicia y el defensor público de Azuay. El objetivo del Tribunal fue escuchar los testimonios sobre criminalización presentados por defensores de derechos humanos y de la naturaleza de Ecuador, y, con base en estos y en el informe de la Defensoría del Pueblo, caracterizar la problemática, ampliar la difusión de la misma y emitir un veredicto que pueda ser presentado en instancias nacionales e internacionales.

En el veredicto del Tribunal ${ }^{55}$ se puso de manifiesto que las comunidades, pueblos y organizaciones sociales y no gubernamentales del Ecuador han sido víctimas, debido a la lucha por sus derechos colectivos y los de la naturaleza, de una práctica cada vez más extendida de criminalización y judicialización, alentada por empresas nacionales y transnacionales - particularmente del sector extractivo-, y ejecutada por diferentes autoridades judiciales, policiales, militares y administrativas, así como fuerzas de seguridad privada. En consecuencia, el Tribunal verificó que existe una «práctica sistemática de criminalización como medio para disciplinar la protesta social y eliminarla» y que la justicia es instrumentalizada para criminalizar a los defensores de la naturaleza. Mientras tanto, la justicia permanece pasiva frente a las violaciones de los derechos humanos de que son víctimas los defensores de la naturaleza y la naturaleza misma.

El Tribunal, en su veredicto, encuentra probado lo siguiente:

1. Existe un patrón de criminalización. Los casos son demostrativos de una práctica sistemática de criminalización como medio para disciplinar la protesta social y eliminarla.

2. Existe una desigualdad enorme en la aplicación de la justicia. Mientras la justicia es instrumentalizada para criminalizar a las

54 Para más información, visitar la página oficial del encuentro en http://www.aguaypachamama.org/ y también http://movimientos.org/madretierra/pachagua/Convocatoria.pdf.

55 Ver Veredicto del Tribunal Ético ante la Criminalización de Defensores y Defensoras de los Derechos Humanos y de la Naturaleza. Cuenca, Ecuador, 22 y 23 de junio de 2011 (http://servindi.org/pdf/ TribunalEtico23Jun2011.pdf). 
defensoras y los defensores de la naturaleza, esta permanece pasiva frente a las violaciones de los derechos humanos de que ellos y la naturaleza son víctimas.

3. Las defensoras y los defensores de la naturaleza y sus familias están indefensos. La criminalización pone en situación de vulnerabilidad a las personas criminalizadas, a sus familias y a su entorno comunitario, y a los operadores oficiales que se atreven a emitir fallos favorables a los defensores.

4. La naturaleza - Pachamama - está indefensa al privarla de sus defensores. Sin defensores, materializar el sumak kawsay es imposible.

En consecuencia, el mismo Tribunal formula una serie de recomendaciones para el Poder Ejecutivo, el Poder Legislativo, el Poder Judicial, los funcionarios encargados de hacer cumplir la ley, el Poder Público en su conjunto, los medios de comunicación, la comunidad internacional y las comunidades y organizaciones.

Al Poder Ejecutivo le recomienda que se abstenga de expresar en sus discursos o declaraciones contenidos que deslegitimen o que estigmaticen a los defensores y defensoras de los derechos humanos y de la naturaleza; que no interfiera en las decisiones que deban tomar los funcionarios de la rama judicial, especialmente cuando se trate de procesamiento penal a las personas miembros de organizaciones no gubernamentales; que se abstenga de diseñar y llevar a cabo proyectos extractivistas, dado que estos no se ajustan al mandato constitucional del sumak kausay; que se abstenga de poner en falsa confrontación el interés público, fundado en el poder de las mayorías, con el interés de las minorías más vulnerables, pues con ello se desconoce la pluralidad de intereses legítimos que conforman el país y la legitimidad de la lucha por los derechos humanos y de la naturaleza; que se disponga a corregir y retractarse de las declaraciones públicas realizadas hasta el momento en las cuales menosprecia y estigmatiza a los defensores y defensoras de los derechos humanos y de la naturaleza. El presidente debe pedir perdón como parte de una reparación integral que les adeuda; debe también encaminar las políticas públicas hacia una armónica relación entre los seres humanos y entre estos y la Pachamama; y debe disponerse a entablar relaciones sanas y libres, sin ningún tipo de discriminación, con las personas, organizaciones, comunidades y pueblos. En el caso específico de las organizaciones, se debe derogar cualquier disposición que las afecte buscando disolverlas o incidir sobre sus estatutos.

Al Poder Legislativo le recomienda que se abstenga de emitir normas contrarias a la Constitución Nacional, particularmente aquellas que afecten la participación, la libre expresión y la consulta de decisiones

EL DERECHO

A DEFENDER

EL MEDIO

AMBIENTE: LA

PROTECCIÓN DE

LOS DEFENSORES

Y DEFENSORAS

AMBIENTALES

THE RIGHT TO

DEFEND THE

ENVIRONMENT:

THE PROTECTION

OFTHE

ENVIRONMENTAL

DEFENDERS 
relacionadas con los derechos humanos de los pueblos y de la naturaleza. A su vez, se le recomienda que se apegue a sus atribuciones estrictamente constitucionales y no interfiera indebidamente en los quehaceres de otras ramas del poder o en organismos de control propios del Estado. Y, finalmente, recomienda derogar los artículos del Código Penal que se están utilizando para criminalizar a las defensoras y a los defensores de los derechos humanos y de la naturaleza, particularmente el que hace referencia al terrorismo, pues es desproporcionado y va en contravía del sumak kawsay.

Al Poder Judicial le recomienda que se abstenga de procesar miembros de organizaciones o pueblos que defiendan los derechos colectivos y de la naturaleza, acogiéndose al principio de que el derecho penal es el último recurso. También le recomienda que se disponga a dar cumplimiento a las amnistías otorgadas por la Asamblea Constituyente; además se le recomienda archivar todos los procesos iniciados contra las personas, organizaciones y pueblos defensores de los derechos humanos y de la naturaleza. Y que ordene la reparación integral de las víctimas de criminalización, sus familias y entorno social (esto incluye la petición de perdón por parte del presidente de la República y su compromiso de no volver a criminalizar a las organizaciones sociales). Además se le recomienda investigar a quienes utilizaron y utilizan a la justicia contra los movimientos sociales.

A los funcionarios encargados de hacer cumplir la ley les pide no utilizar la violencia para contener las protestas sociales; proteger a las comunidades cuando se vean amenazadas por la industria extractiva; no realizar operaciones militares en las tierras de comunidades campesinas y territorios de las comunas, pueblos y nacionalidades indígenas, afrodescendiente y montubio. Al poder público en su conjunto se le solicita detener de inmediato los proyectos extractivos que destruyen la naturaleza; que se reestructure el Poder Judicial con carácter plurinacional, incluyendo los derechos colectivos y de la naturaleza y la jerarquía de la justicia indígena.

A los medios de comunicación se les recomienda informar con la verdad acerca de los hechos en los que participan los movimientos sociales y en defensa de la naturaleza; darle a las comunidades el mismo espacio que se da a las autoridades y a las empresas. A la comunidad internacional se le recomienda vigilar y exigir al Estado ecuatoriano el cumplimiento de las normas y compromisos internacionales de derechos humanos ya adquiridos. Y, finalmente, a las comunidades y organizaciones, con base en la ética de la existencia y la ética de la resistencia y ejerciendo la no violencia activa, les recomienda mantenerse en la defensa de sus derechos y los de la naturaleza para defender el sueño del sumak kawsay. 


\section{V.2. Fondos de protección y defensa}

El «Fondo de Protección Defender la Tierra ${ }^{56}$ tiene como finalidad proveer ayuda directa a organizaciones y defensores y defensoras del derecho a la tierra, al territorio y derechos relacionados que se encuentren en riesgo por su labor en Colombia. Asimismo, genera mecanismos de acompañamiento y comunicación con las organizaciones y defensores y defensoras del derecho a la tierra, al territorio y derechos relacionados seleccionados para la provisión de ayudas directas; elabora informes de riesgo sobre la situación de organizaciones y defensores y defensoras del derecho a la tierra, al territorio y derechos relacionados; e incide en la política pública sobre la situación de organizaciones y defensores del derecho a la tierra, al territorio y derechos relacionados en Colombia, así como en el Sistema Interamericano y Universal de Derechos Humanos.

Pueden beneficiarse del Fondo las organizaciones de base y organizaciones no gubernamentales, y sus integrantes (así como su núcleo familiar), que trabajen por la garantía del derecho a la tierra, al territorio y derechos relacionados, que se encuentren en riesgo de sufrir agresiones por el desarrollo de esta labor. También pueden recurrir al Fondo los defensores y defensoras del derecho a la tierra, al territorio y derechos relacionados que se encuentren en riesgo de sufrir agresiones por el desarrollo de esta labor; y las comunidades, y sus integrantes (así como su núcleo familiar), que se encuentren en riesgo de sufrir agresiones relacionadas con la defensa de los mencionados derechos.

La ayuda que proporciona este Fondo incluye el traslado urgente a otro lugar cuando el defensor o su núcleo familiar se encuentre en riesgo inminente de sufrir atentados contra su vida o su seguridad personal; el traslado y reubicación temporal para facilitar el traslado y los medios de subsistencia del defensor y su núcleo familiar a otro lugar que le otorgue condiciones adecuadas de protección de su vida o integridad personal; los gastos de asistencia y representación legal para que el defensor o las organizaciones de base puedan realizar su defensa judicial en caso de estar inmersos en procesos de judicialización; el apoyo financiero (suma global) a la familia en caso de muerte del defensor; y demás actividades colectivas de protección y autoprotección.

El monto de la ayuda no puede exceder, en ningún caso, la suma de cuatro millones quinientos mil pesos colombianos (dos mil quinientos dólares americanos). La duración de la ayuda no podrá exceder en

56 Este Fondo se creó a raíz de las experiencias de cinco fondos de protección de la sociedad civil en Colombia, en concreto, de Somos Defensores. Programa No Gubernamental de Protección a Defensores de Derechos Humanos; el Fondo para Ayudas de Emergencia y Fortalecimiento Organizacional en Protección y Autoprotección; el Fondo de Acción Urgente de América Latina y el Caribe Hispano-Hablante para los Derechos de la Diversidad de las Mujeres; el Programa de Salida Temporal de Colombianos de Secretariado Nacional de Pastoral Social Cáritas Colombiana y el Fondo de Emergencia Humanitario de Amnistía Internacional. Para más información consultar www. landcoalition.org/es/global-initiatives/los-defensores-de-los-derechos-humanos ywww.cinep.org.co/.

\section{EL DERECHO \\ A DEFENDER \\ EL MEDIO \\ AMBIENTE: LA \\ PROTECCIÓN DE \\ LOS DEFENSORES \\ Y DEFENSORAS \\ AMBIENTALES}

THE RIGHTTO

DEFEND THE

ENVIRONMENT:

THE PROTECTION

OFTHE

ENVIRONMENTAL

DEFENDERS 
ningún caso los seis meses. En algunos casos se podrá valorar la extensión de este plazo teniendo en cuenta condiciones especiales de seguimiento del caso.

\section{V.3. La asistencia legal de los defensores ambientales}

En la actualidad existen organizaciones como el Centro Legal de Defensores del Medio Ambiente (EDLC) que protege los derechos humanos de personas y comunidades en países en desarrollo que luchan contra el daño a su ambiente. El programa original y más importante del EDLC es reclutar a los mejores abogados y bufetes jurídicos estadounidenses y europeos para proteger los derechos humanos de las personas y comunidades en países en vías de desarrollo que luchan en defensa de su medio ambiente. Los juristas pertenecientes a este programa son abogados que defienden, negocian o litigan de forma gratuita (pro bono).

La asistencia jurídica proporcionada por el EDLC consiste en ayudar a individuos defensores del medio ambiente que son acusados en enjuiciamientos penales políticamente motivados; negociar o litigar a nombre de grupos que enfrentan daños de proyectos que afectan su tierra, estilo de vida, y medio ambiente; luchar contra la impunidad por violaciones de los derechos humanos de defensores del medio ambiente; llevar adelante los reclamos de los pueblos indígenas por sus tierras tradicionales; preparar memoriales sobre temas legales que se relacionen con los derechos humanos y el medio ambiente en casos presentados a los tribunales y ante los organismos internacionales de derechos humanos; y proveer asistencia legal institucional a organizaciones que trabajan con defensores del medio ambiente o promover los derechos humanos ambientales.

\section{V.4. Programas de protección}

Una de las organizaciones sin fines de lucro y que focaliza su misión en proteger a los defensores ambientales es la Protection International. Esta organización proporciona mecanismos de protección e instrumentos de gestión de la seguridad a los defensores de derechos humanos en general y, en particular, a los que protegen el medio ambiente y los derechos ambientales de otras personas, y que se encuentran en una situación de riesgo. El apoyo conferido a estas personas se realiza mediante programas de protección integral que ayudan a los defensores a reforzar sus capacidades con el fin de gestionar su protección de forma efectiva, de permitir que aquellos que los deben proteger cumplan con sus obligaciones, y de convencer a otras instituciones e individuos con capacidad de influencia de que maximicen los esfuerzos para procurar dicha protección. Desde el año 2004, Protection International ha trabajado con colaboradores locales en más de treinta países de todo 
el mundo ${ }^{57}$ y forma parte de la Human Rights and Democracy Network (HRDN), un grupo informal de organizaciones no gubernamentales que opera a nivel de la Unión Europea en el ámbito de los derechos humanos, la democracia y la prevención de conflictos.

Otra organización es Front Line Defenders creada en el año 2001 con el objetivo específico de proteger los derechos humanos de los defensores en situación de riesgo, personas que trabajan para la defensa de los derechos consignados en la Declaración Universal de Derechos Humanos. Esta organización no solo proporciona protección necesaria a estas personas, sino que en casos de emergencia puede facilitar el desplazamiento temporal de los defensores de derechos humanos en riesgo, incluidos los que defienden el medio ambiente ${ }^{58}$. Asimismo, desde Amnistía se ha creado el International Environmental Defenders Network $(\mathrm{EDeN})^{59}$, con el fin de proteger a aquellas personas que defienden el medio ambiente, además de personas que han sido objeto de desplazamientos forzados por razones ambientales.

Otro ejemplo de programa de protección es el promovido por el Departamento de Justicia y Administración Pública del País Vasco, a través de la Dirección de Derechos Humanos, que durante el año 2011 puso en marcha el programa de protección temporal de defensores y defensoras de derechos humanos. Este programa, si bien es un programa a favor de los defensores de derechos humanos en general, incluye a los defensores ambientales. Actualmente es un programa en curso y no constituye una obligación legal ni en el derecho internacional ni en el derecho español, pero sí está fuertemente recomendado en el ámbito primero $^{60} \mathrm{y}$ tiene marco legal a escala europea ${ }^{61} \mathrm{y}$ española ${ }^{62}$. El objetivo que se pretende con este programa es otorgar protección a los defensores y defensoras de derechos humanos, incluidos los defensores ambientales, que son gravemente amenazados, a través de la acogida temporal. De esta forma, se puede acoger temporalmente a personas físicas de una nacionalidad diferente a la española, vinculadas a organizaciones sociales, que se vean amenazadas y perseguidas en su país de origen por su actividad de defensa de los derechos humanos. Se entiende que son

57 Para más información visitar el sitio web: http://protectioninternational.org/human-rights-defenders/ environmental-defenders/.

58 Consultar su página web en: http://www.frontlinedefenders.org/ (consultado el 2 de febrero 2013).

59 Para más información visitar el sitio web: http://www.amnesty.org.nz/get-involved/join-amnesty-team/ join-specialist-network/eden (consultado el 2 de febrero 2013).

60 Vid. Resolución 60/161 (anexo 2) Asamblea General de Naciones Unidas, cit. supra

61 Vid. Directrices de la Unión Europea, 14 de junio 2004, cit supra.

62 Vid. Real Decreto 1257/2007, de 21 de septiembre, por el que se aprueban las normas reguladoras de la concesión directa de ayudas a personas que se vean amenazadas o perseguidas por su actividad en defensa de los derechos humanos, en sus países de residencia habitual fuera de España. Boletín Oficial del Estado, núm. 238 de 4 de octubre de 2007, páginas 40302 a 40304 (3 págs.). Según el artículo 1.2 de este Real Decreto: «... las actuaciones de atención humanitaria objeto de las ayudas irán dirigidas a facilitar la salida de defensores y defensoras de derechos humanos del país en el que residan...».

EL DERECHO

A DEFENDER

EL MEDIO

AMBIENTE: LA

PROTECCIÓN DE

LOS DEFENSORES

Y DEFENSORAS

AMBIENTALES

THE RIGHT TO

DEFEND THE

ENVIRONMENT:

THE PROTECTION

OFTHE

ENVIRONMENTAL

DEFENDERS 
personas amenazadas quienes sufren un riesgo concreto y sustancial contra su seguridad y/o la de sus familiares por razón de su actividad en defensa de los derechos humanos ${ }^{63}$.

\section{REFLEXIONES FINALES}

Los defensores ambientales están muy expuestos a atentados contra su integridad física, a menudo a manos de actores no estatales, y muchos son asesinados por el trabajo que desempeñan en relación con las industrias extractivas y los proyectos de desarrollo, o en relación con el derecho a la tierra de los pueblos indígenas y las minorías. Después de todo lo analizado anteriormente y para hacer frente a esta situación de violencia y desprotección de los defensores ambientales, sería oportuno tener en consideración las siguientes recomendaciones.

En primer lugar, es necesario un reconocimiento de esta situación. Solo cuando se reconoce se puede proteger. En este sentido, los Estados deben reconocer plenamente la importante labor llevada a cabo por los defensores que trabajan en cuestiones ambientales, labor que trata de alcanzar un equilibrio entre el desarrollo económico y el respeto del medio ambiente, considerando el derecho a usar la tierra, la riqueza y los recursos naturales y los derechos de determinados grupos, como las minorías y los pueblos indígenas.

En segundo lugar, tras el reconocimiento, sería conveniente fortalecer los mecanismos institucionales de protección a las defensoras y los defensores ambientales. Con frecuencia, los ataques a los defensores ambientales quedan en la impunidad, lo cual agrava la situación de desprotección de derechos, a la vez que genera sufrimiento y angustia en violación del derecho a la integridad personal. En consecuencia, no solo se debería investigar de manera exhaustiva los ataques perpetrados con el debido proceso legal, sino que debería fortalecerse el rol sancionatorio del Estado para responder adecuadamente a los ataques contra los defensores ambientales. Asimismo, se evidencia que los administradores de justicia en general tienen un desconocimiento sobre qué es un defensor ambiental. El conocimiento del contexto social y personal contribuiría a la investigación, conocimiento y resolución de las causas en las que se encuentren inmersos las defensoras o los defensores. Esta falta de conocimiento está contribuyendo a la criminalización de las defensoras y los defensores.

63 Para más información sobre este Programa consultar: http://www.jusap.ejgv.euskadi.net/r47-dhlinea5/ es/contenidos/informacion/ddhh_defensores_defensoras/es_ddhh/adjuntos/PROGRAMA\%20 DEFENSORES\%20I.pdf y también ver la Orden de 30 de abril de 2012, de la Consejera de Justicia y Administración Pública, por la que convoca y regula el procedimiento de selección de las personas que serán acogidas en el Programa de Protección Temporal para Defensores y Defensoras de los Derechos Humanos durante el ejercicio 2012. 
Por este motivo, deben promoverse mecanismos nacionales de protección, como las defensorías del pueblo, independientes y con facultades de investigación y de recomendación efectivas; la elaboración de programas nacionales de protección a defensores; y la adopción de medidas de protección como los servicios de asistencia rápida, la atención urgente e incluso la relocalización, o la protección de testigos en casos de amenazas. En relación con lo anterior, y en tercer lugar, los Estados no deben tolerar que los medios o los funcionarios públicos estigmaticen la actividad de estos defensores, en particular en contextos de polarización social, puesto que ello puede fomentar un clima de intimidación y acoso que podría generar rechazo e incluso actos de violencia contra estos defensores.

En cuarto lugar, el marco normativo ambiental también puede contribuir a la protección de los defensores ambientales, fortaleciendo la capacidad fiscalizadora y sancionadora del Estado. Asimismo, la mejora del marco normativo relativo a las actividades industriales y su fiscalización permitiría que el Estado pueda garantizar el goce efectivo de los derechos de las comunidades afectadas por su impacto, reconociendo el vínculo existente entre degradación ambiental y protección de los derechos humanos. El Estado, como garante de los derechos protegidos por el derecho internacional de los derechos humanos, debe implementar en consecuencia un marco regulatorio adecuado que proteja efectivamente los derechos de las personas, inclusive la de los defensores ambientales.

En quinto lugar, se recomienda reconocer e implementar el derecho al consentimiento libre, previo e informado de las comunidades afectadas por dichas actividades con un elevado impacto ambiental. En este sentido, no es posible desarrollar mecanismos de participación cuando las personas que participan son amenazadas, asesinadas o desaparecidas. En virtud del derecho al consentimiento libre, previo e informado, le corresponde a la comunidad potencialmente afectada decidir si acepta o no un determinado proyecto, de manera que los derechos de las personas y comunidades, incluyendo los derechos de los defensores ambientales, no pueden quedar subordinados a los intereses económicos de determinadas empresas.

Y, por último, los Estados deben combatir la impunidad de quienes atentan contra estos defensores y sus derechos. En particular, se debe reconocer, por una parte, la responsabilidad de los países de nacionalidad de las industrias y empresas multinacionales por la violencia que generan las actividades desarrolladas sin consentimiento; y, por otra, la responsabilidad de los actores no estatales y quienes actúan en connivencia con ellos, garantizando una investigación pronta e imparcial de las denuncias y reparaciones e indemnizaciones adecuadas para las

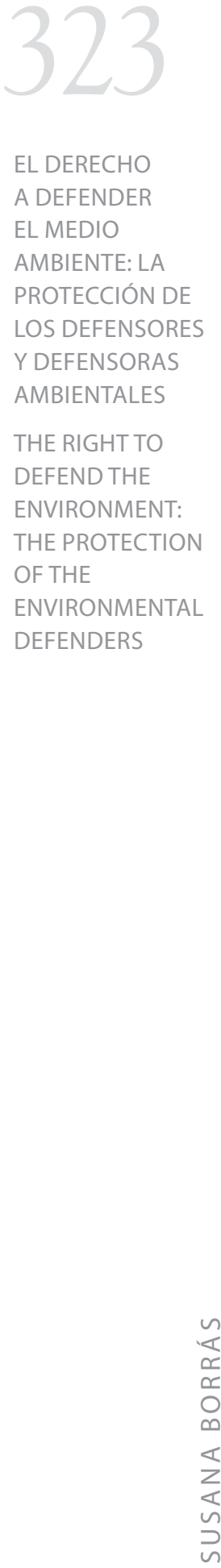


víctimas. Sin duda, la falta de regulación del ejercicio jurisdiccional de las cortes de los países de nacionalidad de las industrias por violaciones de derechos humanos cometidas por las empresas fuera del territorio nacional constituye una de las limitaciones más importantes para procurar la protección de los defensores ambientales. Por este motivo, resulta indispensable que los países de la nacionalidad de las empresas regulen estándares mínimos de conducta y acceso a la justicia. 